\title{
Correlation between serum parathyroid hormone levels and coronary artery calcification in patients without renal failure
}

\author{
GANG-YONG WU, BAI-DA XU, TING WU, XIAO-YING WANG, TIAN-XIAO WANG, \\ XIAO ZHANG, XIAO WANG, YANG XIA and GANG-JUN ZONG
}

Department of Cardiology, the 101st Hospital of the People's Liberation Army, Wuxi, Jiangsu 214044, P.R. China

Received July 17, 2016; Accepted September 12, 2016

DOI: $10.3892 /$ br.2016.761

\begin{abstract}
The aim of the present study was to investigate the correlation between serum parathyroid hormone (PTH) levels and coronary artery calcification (CAC) in patients without renal failure, as well as to determine independent risk factors of CAC score (CACS). A total of 157 patients who underwent coronary computed tomography angiographic examination at the 101th Hospital of the People's Liberation Army between December 2013 and February 2015 were retrospectively evaluated. The correlation between PTH levels and CACS was determined using a Pearson correlation analysis. A receiver operating characteristic (ROC) curve was drawn to determine the best cutoff PTH level for prediction of CAC. The independent association between serum PTH levels and CAC was analyzed by using a logistic regression analysis model with the response variable Be binary class. The results revealed that PTH levels in patients in the CAC group were significantly higher than those of patients in the non-calcification group. PTH levels were positively correlated with CACS $(r=0.288$, $\mathrm{P}<0.001)$. The ROC curve suggested that a PTH level of $\geq 31.05 \mathrm{pg} / \mathrm{ml}$ was the best cut-off point for the prediction of CAC, with a sensitivity of $80.88 \%$, specificity of $60.67 \%$ and an area under the curve of 0.761 . After including predictive factors for CAC (gender, age, smoking status, diabetes, hypertension, hyperlipidemia, body mass index, glomerular filtration rate and calcium, phosphorus, calcium-phosphorus product, magnesium, PTH, total cholesterol, low-density lipoprotein cholesterol, triglyceride, high-density lipoprotein cholesterol and C-reactive protein levels), the odds ratio of the serum PTH levels regarding the prediction of CAC was 1.050 (95\% confidence interval, 1.027-1.074; $\mathrm{P}<0.001)$. In conclusion, the present study suggested that serum PTH levels are
\end{abstract}

Correspondence to: Dr Gang-Jun Zong, Department of Cardiology, the 101st Hospital of the People's Liberation Army, 101 Xingyuan North Road, Wuxi, Jiangsu 214044, P.R. China

E-mail: zonggangjun@ahmu.edu.cn

Key words: parathyroid hormone, coronary artery disease, calcinosis, computed tomography angiography correlated with CAC in patients without renal failure and may thus be used as a reliable predictor of CAC.

\section{Introduction}

Coronary artery calcification (CAC) is a basic pathological change in coronary atherosclerotic heart disease and often indicates further morbidities $(1,2)$. Currently, the most common method of assessment of calcification is multislice computed tomography, and calcification is calculated by using methods such as Agatston, quality and volume integrals. The parathyroid hormone (PTH) is a linear peptide comprising 84 amino acids secreted by parathyroid lord cells, which are mainly implicated in the regulation of calcium phosphorus metabolism. Previous studies have shown that PTH induces high blood pressure and myocardial hypertrophy, is closely associated with heart failure and can even predict the occurrence of coronary heart disease (3-6). In recent years, the association between PTH and CAC has become a research hotspot. The results of previous studies suggested that PTH levels were not associated with the baseline CAC score (CACS), but with CAC progression (7-11). All of the patients included in these studies suffered from kidney failure with or without hemodialysis. However, whether PTH levels are positively correlated with $\mathrm{CAC}$ in patients without renal failure has remained elusive. The purpose of the present study was to investigate the correlation between serum PTH levels and $\mathrm{CAC}$ in patients without renal failure, as well as independent risk factors of CACS.

\section{Materials and methods}

Patients. A total of 225 consecutive patients who underwent coronary CTA examination at the 101th Hospital of the People's Liberation Army (PLA) (Wuxi, China) between December 2013 and February 2015 were retrospectively evaluated. After excluding patients with acute myocardial infarction, heart valve disease, heart failure, a glomerular filtration rate $<60 \mathrm{ml} / \mathrm{min}$ or transaminase levels three times higher than the upper limit of the $99 \%$ reference range, malignant tumors, systemic infection, or autoimmune or connective tissue disease, 157 patients were enrolled. Heart failure was diagnosed according to the Chinese heart failure diagnosis and treatment guidelines from 2014 (12). 
Table I. Gender and disease constitution in patients with and without calcification.

\begin{tabular}{|c|c|c|c|c|c|c|c|c|}
\hline Parameter & $\begin{array}{l}\text { No calcification } \\
\text { group } \\
(\mathrm{n}=89)\end{array}$ & $\begin{array}{l}\text { Calcification } \\
\text { group } \\
(\mathrm{n}=68)\end{array}$ & $\chi^{2}$ & P-value & $\begin{array}{c}\mathrm{CACS} \leq 100 \\
(\mathrm{n}=118)\end{array}$ & $\begin{array}{c}\text { CACS }>100 \\
(n=39)\end{array}$ & $\chi^{2}$ & P-value \\
\hline Males, n (\%) & $49(55.06)$ & $41(60.29)$ & 0.432 & 0.511 & $67(56.78)$ & $23(58.97)$ & 0.058 & 0.810 \\
\hline CAD, n (\%) & $23(25.84)$ & $56(82.35)$ & 49.241 & $<0.001$ & $44(37.29)$ & 35 (89.74) & 32.263 & 0.000 \\
\hline Hypertension, n (\%) & $60(67.42)$ & $54(79.41)$ & 2.789 & 0.095 & $85(72.03)$ & $29(74.36)$ & 0.080 & 0.778 \\
\hline Diabetes, n (\%) & $12(13.48)$ & $14(20.59)$ & 1.408 & 0.235 & $16(13.56)$ & $10(25.64)$ & 3.096 & 0.078 \\
\hline Hyperlipaemia, n (\%) & $17(19.10)$ & $10(14.71)$ & 0.523 & 0.470 & $22(18.64)$ & $5(12.82)$ & 0.698 & 0.403 \\
\hline Smoking, n (\%) & $17(19.10)$ & $24(35.29)$ & 5.239 & 0.022 & $28(23.73)$ & $13(33.33)$ & 1.401 & 0.236 \\
\hline Alcohol, n (\%) & $2(2.25)$ & 7 (10.29) & 3.250 & 0.071 & $7(5.93)$ & $2(5.13)$ & 0.035 & 0.851 \\
\hline Cardiomyopaty, n (\%) & $0(0)$ & $0(0)$ & - & - & $0(0)$ & $0(0)$ & - & - \\
\hline Atrial fibrillation, $\mathrm{n}(\%)$ & $5(5.62)$ & $2(2.94)$ & 0.172 & 0.678 & $7(5.93)$ & $0(0)$ & 1.229 & 0.268 \\
\hline
\end{tabular}

CAD, coronary artery disease; CACS, coronary artery calcification score.

The Medical Ethics Committee of The 101th Hospital of the PLA approved the present retrospective study (protocol no. 20150052). Each patient signed a consent form agreeing to the storage of their information in the hospital's database and use for scientific studies.

Experimental methods. Patient data regarding hypertension, diabetes, hyperlipidemia, as well as history of smoking and alcohol consumption were collected and patients were stratified according to their positive or negative status. The body mass index (BMI) was calculated by dividing weight by the square of the height.

A total of $3 \mathrm{ml}$ venous blood had been taken from each patient in the fasting state and subjected to laboratory analysis. Total cholesterol (TC), electrolytes, triglycerides (TGs), C-reactive protein (CRP), creatinine, high-density lipoprotein cholesterol (HDL-C), low-density lipoprotein cholesterol (LDL-C) and fasting blood glucose (FBG) levels were measured with an automatic biochemical analyzer (AU5800; Olympus, Tokyo, Japan). Serum PTH levels were measured using a chemiluminescence method (PTH ELISA kit; GETEIN Co., Nanjing, China). The glomerular filtration rate (GFR) was calculated by using the equation: GFR $\left(\mathrm{ml} / \mathrm{min} \times 73 \mathrm{~m}^{-2}\right)=[140-$ age (years)] $\mathrm{x}$ weight $(\mathrm{Kg}) / 0.818 \mathrm{x}$ creatinine concentration $(\mu \mathrm{mol} / \mathrm{l})$. For women, the resulting value was multiplied by 0.85 .

For coronary computed tomography (CT) scanning, the Toshiba 320 row spiral CT scanner (Toshiba, Tokyo, Japan) was used. The CACS was calculated by using a Toshiba vital 6.2 workstation (Toshiba, Tokyo, Japan) according to the Agatston integral (13), which was operated by a technician. Patients with CACS $>0$ were assigned to the $\mathrm{CAC}$ group.

Heart Doppler examination was performed by cardiac ultrasonography using an ultrasonographic diagnostic instrument (vivid E9; GE Healthcare, Little Chalfont, UK), through which degenerative heart valve disease was diagnosed.

Statistical analysis. All statistical analyses were performed by using SPSS 15.0 (SPSS, Inc., Chicago, IL, USA).
Continuous variables were presented as the mean \pm standard deviation, and analysis of variance and least significant difference tests were applied to compare differences between groups. Categorical variables were presented as percentages and determined by using the $\chi^{2}$ test. The Pearson rank order was used to analyze the correlations. A receiver operating characteristic (ROC) curve was drawn to determine the predictive value of PTH for CAC. The best cut-off PTH level to predict CAC was determined by using PTH values that provide the maximum sum of sensitivity and specificity. Indicators including gender, age, smoking status, diabetes, hypertension, hyperlipidemia, BMI, GFR, levels of serum calcium, serum phosphorus, calcium-phosphorus product (CPP), serum magnesium, PTH, TC, LDL-C, TG, HDL-C and CRP were assessed using the logistic regression analysis model with the response variable Be binary class in order to determine independent factors correlated with CAC, presented as odds ratio (OR) and $95 \%$ confidence interval (CI). $\mathrm{P}<0.05$ was considered to indicate a statistically significant difference.

\section{Results}

Patient data. The present study included 68 patients with CAC, comprising 41 men and 27 women, with a mean CACS of $402.49 \pm 666.3$ and serum PTH levels of $48.70 \pm 21.39 \mathrm{pg} / \mathrm{ml}$ (range, $20.40-123 \mathrm{pg} / \mathrm{ml}$; normal, $14-72 \mathrm{pg} / \mathrm{ml}$ ), and 89 patients without CAC, including 49 men and 40 women, with a mean serum PTH level of $31.98 \pm 16.03 \mathrm{pg} / \mathrm{ml}(12.00-86.90 \mathrm{pg} / \mathrm{ml})$. The two groups displayed statistically significant differences in terms of age, PTH levels, GFR and blood phosphorus level, smoking status and frequency of coronary heart disease $(\mathrm{P}<0.05)$. However, no significant differences were observed in BMI, calcium, magnesium, CPP, cholesterol, FBG and CRP levels, as well as gender, hypertension, diabetes, hyperlipidemia and alcohol use $(\mathrm{P}>0.05)$.

In addition, the 157 patients were further stratified based on the CACS as follows: CACS $\leq 100(n=118$ patients) and CACS $>100(n=39)$. The two groups only significantly differed 
Table II. Clinical and biochemical parameters of patients with and without calcification.

\begin{tabular}{|c|c|c|c|c|c|c|c|c|}
\hline Parameter & $\begin{array}{l}\text { No calcification } \\
\text { group } \\
(n=89)\end{array}$ & $\begin{array}{l}\text { Calcification } \\
\text { group } \\
(\mathrm{n}=68)\end{array}$ & t-value & P-value & $\begin{array}{c}\mathrm{CACS} \leq 100 \\
(n=118)\end{array}$ & $\begin{array}{c}\text { CACS }>100 \\
\quad(n=39)\end{array}$ & t-value & P-value \\
\hline Age (years) & $59.82 \pm 11.50$ & $68.38 \pm 10.05$ & 4.879 & $<0.001$ & $60.94 \pm 11.01$ & $71.36 \pm 10.09$ & 5.228 & $<0.001$ \\
\hline BMI $\left(\mathrm{kg} / \mathrm{m}^{2}\right)$ & $24.86 \pm 3.28$ & $23.94 \pm 3.39$ & 1.725 & 0.087 & $24.65 \pm 3.28$ & $23.91 \pm 3.54$ & 1.203 & 0.231 \\
\hline PTH (pg/ml) & $31.98 \pm 16.03$ & $48.70 \pm 21.39$ & 5.391 & $<0.001$ & $35.87 \pm 19.68$ & $49.37 \pm 18.76$ & 3.755 & $<0.001$ \\
\hline $\operatorname{GFR}\left(\mathrm{ml} / \mathrm{min} / 1.73 \mathrm{~m}^{2}\right)$ & $102.16 \pm 29.54$ & $84.49 \pm 22.47$ & 4.108 & $<0.001$ & $98.97 \pm 28.43$ & $80.99 \pm 22.15$ & 3.603 & $<0.001$ \\
\hline $\mathrm{Ca}(\mathrm{mmol} / \mathrm{l})$ & $2.28 \pm 0.13$ & $2.28 \pm 0.15$ & 0.088 & 0.930 & $2.28 \pm 0.13$ & $2.27 \pm 0.15$ & 0.725 & 0.470 \\
\hline $\mathrm{Mg}(\mathrm{mmol} / \mathrm{l})$ & $0.81 \pm 0.09$ & $0.82 \pm 0.08$ & 0.043 & 0.966 & $0.81 \pm 0.09$ & $0.83 \pm 0.09$ & 1.264 & 0.208 \\
\hline $\mathrm{P}(\mathrm{mmol} / \mathrm{l})$ & $1.12 \pm 0.16$ & $1.07 \pm 0.18$ & 2.095 & 0.038 & $1.11 \pm 0.17$ & $1.06 \pm 0.18$ & 1.715 & 0.088 \\
\hline $\mathrm{CPP}\left(\mathrm{mmol}^{2} / \mathrm{l}^{2}\right)$ & $2.57 \pm 0.42$ & $2.43 \pm 0.44$ & 1.971 & 0.050 & $2.54 \pm 0.42$ & $2.40 \pm 0.46$ & 1.755 & 0.081 \\
\hline FBG (mmol/l) & $5.36 \pm 1.35$ & $5.54 \pm 1.40$ & 0.828 & 0.409 & $5.41 \pm 1.35$ & $5.54 \pm 1.44$ & 0.524 & 0.601 \\
\hline TC (mmol/l) & $4.26 \pm 0.90$ & $4.11 \pm 0.91$ & 1.019 & 0.310 & $4.21 \pm 0.88$ & $4.17 \pm 0.99$ & 0.201 & 0.841 \\
\hline TG (mmol/l) & $1.81 \pm 1.26$ & $1.60 \pm 1.41$ & 0.962 & 0.338 & $1.74 \pm 1.15$ & $1.65 \pm 1.77$ & 0.393 & 0.695 \\
\hline HDL-C (mmol/l) & $1.23 \pm 0.29$ & $1.18 \pm 0.26$ & 1.145 & 0.254 & $1.22 \pm 0.29$ & $1.19 \pm 0.25$ & 0.586 & 0.559 \\
\hline LDL-C (mmol/l) & $2.05 \pm 0.67$ & $2.04 \pm 0.69$ & 0.080 & 0.936 & $2.04 \pm 0.66$ & $2.06 \pm 0.74$ & 0.103 & 0.918 \\
\hline CRP (mg/l) & $3.07 \pm 7.05$ & $7.07 \pm 18.81$ & 1.668 & 0.099 & $4.51 \pm 14.60$ & $5.68 \pm 9.88$ & 0.467 & 0.641 \\
\hline
\end{tabular}

Values are expressed as the mean \pm standard deviation. CACS, coronary artery calcification score; BMI, body mass index; PTH, parathyroid hormone; GFR, glomerular filtration rate; Ca, calcium; Mg, magnesium; P, inorganic phosphate; CPP, calcium-phosphorus product; FBG, fasting blood glucose; TC, total cholesterol; LDL-C, low-density lipoprotein cholesterol; HDL-C, high-density lipoprotein cholesterol; TG, triglycerides; CRP, C-reactive protein.

Table III. Correlation analysis for parathyroid hormone and biological metabolic parameters.

\begin{tabular}{lcc}
\hline Parameter & r-value & P-value \\
\hline GFR & -0.207 & 0.011 \\
Calcium & 0.023 & 0.778 \\
Magnesium & 0.006 & 0.945 \\
Inorganic phosphate & -0.231 & 0.005 \\
CPP & -0.225 & 0.006 \\
FBG & 0.139 & 0.092 \\
TC & 0.011 & 0.892 \\
TG & -0.029 & 0.726 \\
HDL-C & 0.051 & 0.538 \\
LDL-C & -0.032 & 0.702 \\
CRP & -0.033 & 0.690 \\
\hline
\end{tabular}

GFR, glomerular filtration rate; CPP, calcium-phosphorus product; FBG, fasting blood glucose; TC, total cholesterol; TG, triglycerides; HDL-C, high-density lipoprotein cholesterol; LDL-C, low-density lipoprotein cholesterol; CRP, C-reactive protein.

Table IV. Correlation analysis for parathyroid hormone and calcification scores.

\begin{tabular}{lcc}
\hline Group & r-value & P-value \\
\hline Calcification + no calcification & 0.288 & $<0.001$ \\
Calcification & 0.186 & 0.130 \\
\hline
\end{tabular}

Table V. Parathyroid hormone levels in patients with three degrees of CAC.

\begin{tabular}{lcccc}
\hline & & \multicolumn{2}{c}{$\begin{array}{c}95 \% \text { CI for } \\
\text { mean difference }\end{array}$} \\
\cline { 3 - 5 } Groups & P-value & Lower & Upper \\
\hline $\mathrm{CACS} \leq 10$ and $10<\mathrm{CACS}<100$ & $<0.001$ & -28.19 & -10.28 \\
$\mathrm{CACS} \leq 10$ and $\mathrm{CACS}>100$ & $<0.001$ & -23.66 & -9.85 \\
$10<\mathrm{CACS} \leq 100$ and $\mathrm{CACS}>100$ & 0.626 & -7.56 & 12.52 \\
\hline
\end{tabular}

CACS, coronary artery calcification score; CI, confidence interval.

in terms of age, PTH levels, GFR and the frequency of coronary heart disease $(\mathrm{P}<0.05)$ (Tables I and II).

Correlation of PTH levels and calcium score as well as metabolic measures. The results of the Pearson correlation analysis showed that among all of the patients included in the present study, the PTH levels were positively correlated with the CACS $(\mathrm{r}=0.288, \mathrm{P}<0.001)$, while they were negatively correlated with the GFR, phosphorus levels and CPP ( $r=-0.207$, $\mathrm{P}=0.011 ; \mathrm{r}=-0.231, \mathrm{P}=0.005$; and $\mathrm{r}=-0.225, \mathrm{P}=0.006$, respectively). However, in the calcification group, no significant correlation was observed in this respect $(\mathrm{r}=0.186, \mathrm{P}=0.130$; Tables III and IV).

Serum PTH levels in patients with $\mathrm{CACS} \leq 10(\mathrm{n}=98)$ were significantly lower than those in patients with $10<\mathrm{CACS} \leq 100$ $(n=20)$ and $C A C S>100 \quad(n=39) \quad(P<0.001$ for each $)$. However, no significant differences were observed in PTH levels 
Table VI. Binary logistic regression analysis of independent predictors for coronary artery calcification.

\begin{tabular}{lcrrrr}
\hline Indicators & $\mathrm{B}$ & Wald & P-value & OR & $95 \%$ CI \\
\hline PTH & 0.049 & 18.231 & $<0.001$ & 1.050 & $1.027-1.074$ \\
Smoking & 0.921 & 4.795 & 0.029 & 2.513 & $1.102-5.731$ \\
GFR & -0.025 & 9.972 & 0.002 & 0.975 & $0.961-0.991$ \\
\hline
\end{tabular}

B, regression coefficient; PTH, parathyroid hormone; GFR, glomerular filtration rate; CI, confidence interval; OR, odds ratio.

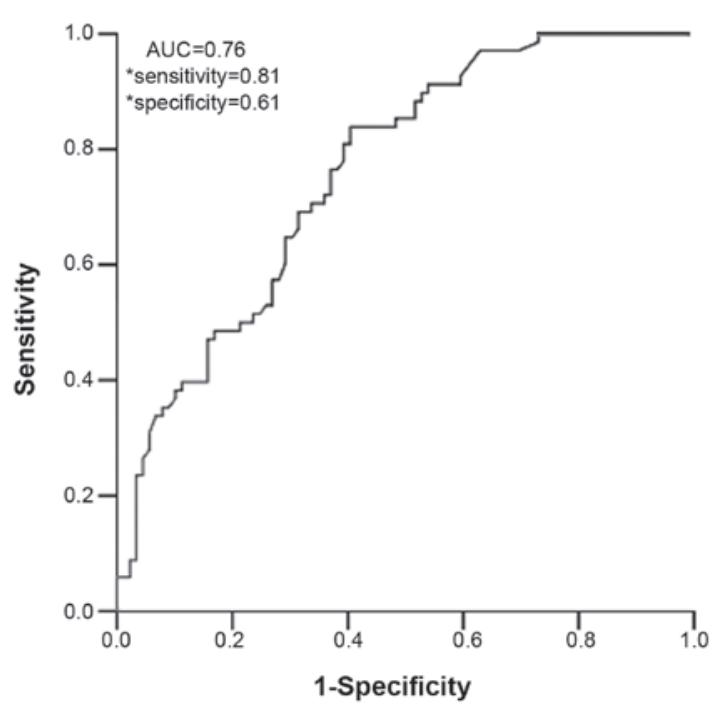

Figure 1. Receiver operating characteristic curve of parathyroid hormone levels for the prediction of coronary artery calcification. "Values were obtained using the optimal cut-off value. AUC, area under the curve.

between patients with $10<\mathrm{CACS} \leq 100$ and $\mathrm{CACS}>100$ $(\mathrm{P}=0.626)($ Table $\mathrm{V})$.

Predictive value of PTH for CAC. The ROC curve revealed that PTH levels of $\geq 31.05 \mathrm{pg} / \mathrm{ml}$ are optimal for the prediction of CAC, with a sensitivity of $80.88 \%$, a specificity of $60.67 \%$ and an area under the curve of $0.76(\mathrm{P}<0.001$; Fig. 1$)$.

Independent predictors of CAC. The results of the logistic regression analysis model with the response variable Be binary class showed that PTH levels (OR=1.050; 95\% CI, 1.050-1.074; $\mathrm{P}<0.001)$ and smoking $(\mathrm{OR}=2.513$; 95\% CI, 2.513-5.731; $\mathrm{P}=0.029)$ were predictors of $\mathrm{CAC}$ and that the GFR $(\mathrm{OR}=0.975$, 95\% CI 0.961-0.991; $\mathrm{P}=0.002$ ) was negatively associated with CAC $(\mathrm{P}<0.05$; Table VI). None of the other factors assessed had any predictive value regarding $\mathrm{CAC}(\mathrm{P}>0.05)$. Overall, the results supported the significance of PTH levels in terms of prediction of CAC.

\section{Discussion}

CAC arises from calcium salt deposition via atheromatous plaque rupture and hemorrhage-induced composite patches. Previous studies have confirmed that hypertension, diabetes, gender, age and other cardiovascular risk factors are involved in the formation of CAC (14). The results of the present study showed that the mean age and smoking status of the patients in the CAC group were significantly higher than those in the non-calcification group, which was consistent with the results of previous studies $(15,16)$. While in the CAC group, the number of patients with high blood pressure and diabetes, and the proportion of men were higher than those in the group without calcification, the difference did not reach statistical significance, possibly due to factors such as the small overall sample size and the fact that the number of patients without calcification was higher than that of patients with calcification.

The degree of CAC can predict the extent of coronary artery stenosis, affect the therapeutic efficacy of coronary artery intervention and predict the incidence of cardiovascular events, regardless of whether patients had clinical symptoms $(17,18)$. Therefore, an accurate prediction of the degree of CAC is significant in clinical practice. In addition to the most commonly used imaging techniques at present, laboratory indexes, including lipoprotein(a), endothelin 1 and bone morphogenetic protein 2 levels, are also associated with calcification and may be utilized to assess the degree of CAC (19-21). To date, the association between serum calcium, phosphorus, CPP and CAC has been most widely discussed in previous studies $(22,23)$; however, the conclusions are not consistent. The presence of cardiovascular risk factors may affect the results of these studies. According to the present consensus, calcification is considered as the result of calcium phosphorus metabolism disorders, transformation of vascular endothelial cells to osteoblasts and calcium balance disorders (24). PTH mainly regulates calcium phosphorus metabolism and vice versa, suggesting a feedback loop-like association between PTH and calcification.

In fact, the results of a previous study indicated that serum PTH levels were able to predict coronary heart disease in subjects with calcium levels within the normal range (6). Hyperparathyroidism impairs coronary microcirculation and PTH was shown to be independently correlated with abnormal coronary flow reserve (25). Furthermore, several studies have pointed out the important effect of PTH overexpression on cardiovascular disease, including carotid artery, abdominal aortic and valvular calcifications, as well as CAC (26-30), while most of these studies focused on patients with renal failure, which is known to induce secondary hyperparathyroidism. However, the results of previous studies are inconsistent with regard to whether renal insufficiency is associated with CAC. Ix et al (31) reported that the association between mild-to-moderate renal insufficiency and CAC was not statistically significant after adjusting cardiovascular risk factors, while Fox et al (32) concluded the opposite. Certain studies have argued that the correlation only existed in patients $>70$ years of age or with stage 3-5 chronic kidney 
disease $(33,34)$. Furthermore, it remains elusive whether renal failure influences the association of PTH levels and CAC. In the present study, in order to avoid interference, patients with GFR $<60 \mathrm{ml} / \mathrm{min}$ were excluded, and PTH remained an independent predictor of CAC after including multiple cardiovascular risk factors; furthermore PTH levels were positively correlated with the CACS in all patients. However, in the calcification group, PTH levels did not show an increasing trend corresponding with the increase in the calcium score, which was different from the results of previous studies $(11,23)$. The small sample size of the calcification group may be one of the reasons for this observation.

All of the abovementioned results indicated that PTH is independently correlated with CAC, irrespective of renal failure being present. Moreover, PTH is easy to detect at low cost, representing advantages over other biomarkers.

The limitations of the present study include, but are not limited to the following points: Patients with heart failure and heart valve disease were excluded; however, the presence of peripheral artery calcification was not known. Calcium metabolism is not only determined by the level of PTH, but vitamin D also has a marked impact on it; however, the levels of vitamin D-associated factors were not available in the present retrospective study. Further limitations of the present study included small sample size and number of parameters available; in addition only a preliminarily analysis of the correlation between PTH levels and CAC was performed. Therefore, the results of the present study only indicated an association, and further studies are therefore required to clarify the detailed mechanisms of the impact of PTH on CAC.

In conclusion, the present study revealed that the serum PTH levels correlated with CAC and may thus be used as a reliable predictor of $\mathrm{CAC}$ in patients without renal failure; however, it remains to be determined whether PTH is an independent predictor of CAC.

\section{Acknowledgements}

The present study was supported by the National Natural Science Fund of China (no. 81371657).

\section{References}

1. Shang CL, Wang Y, Bai J and Chen C: Effect of moderate-severe calcified coronary lesions on immediate outcome of percutaneous coronary intervention. Chin J Geriatr Heart Brain Vessel Dis. 4: 357-360, 2013.

2. Budoff MJ, Shaw LJ, Liu ST, Weinstein SR, Mosler TP, Tseng PH, Flores FR, Callister TQ, Raggi P and Berman DS: Long-term prognosis associated with coronary calcification: Observations from a registry of 25,253 patients. J Am Coll Cardiol 49: 1860-1870, 2007.

3. Demir M, Günay T, Özmen G and Melek M: Relationship between vitamin D deficiency and nondipper hypertension. Clin Exp Hypertens 35: 45-49, 2013.

4. Cha H, Jeong HJ, Jang SP, Kim JY, Yang DK, Oh JG and Park WJ: Parathyroid hormone accelerates decompensation following left ventricular hypertrophy. Exp Mol Med 42: 61-68, 2010.

5. Sugimoto T, Dohi K, Onishi K, Watanabe K, Sato Y, Sugiura E, Nakamori S, Nakajima $\mathrm{H}$, Nakamura $\mathrm{M}$ and Ito $\mathrm{M}$ : Interrelationship between haemodynamic state and serum intact parathyroid hormone levels in patients with chronic heart failure. Heart 99: 111-115, 2013.

6. Kamycheva E, Sundsfjord J and Jorde R: Serum parathyroid hormone levels predict coronary heart disease: The Troms $\varnothing$ Study. Eur J Cardiovasc Prev Rehabil 11: 69-74, 2004.
7. Oka M, Ohtake T, Mochida Y, Ishioka K, Maesato K, Moriya H, Hidaka S and Kobayashi S: Correlation of coronary artery calcification with pre-hemodialysis bicarbonate levels in patients on hemodialysis. Ther Apher Dial 16: 267-271, 2012.

8. Ohtake T, Kobayashi S, Oka M, Furuya R, Iwagami M, Tsutsumi D, Mochida Y, Maesato K, Ishioka K, Moriya H, et al: Lanthanum carbonate delays progression of coronary artery calcification compared with calcium-based phosphate binders in patients on hemodialysis: A pilot study. J Cardiovasc Pharmacol Ther 18: 439-446, 2013.

9. Iyer H, Abraham G, Reddy YN, Pandurangi UM, Kalaichelvan U, Gomathi SB, Mathew M and Santhosham R: Risk factors of chronic kidney disease influencing cardiac calcification. Saudi J Kidney Dis Transpl 24: 1189-1194, 2013.

10. Daniel WT, Weber C, Bailey JA, Raggi P and Sharma J: Prospective analysis of coronary calcium in patients on dialysis undergoing a near-total parathyroidectomy. Surgery 154: 1315-1321, 2013.

11. Malluche HH, Blomquist G, Monier-Faugere MC, Cantor TL and Davenport DL: High parathyroid hormone level and osteoporosis predict progression of coronary artery calcification in patients on dialysis. J Am Soc Nephrol 26: 2534-2544, 2015.

12. Chinese Society of Cardiology of Chinese Medical Association; Editorial Board of Chinese Journal of Cardiology: Chinese guidelines for the diagnosis and treatment of heart failure 2014. Zhonghua Xin Xue Guan Bing Za Zhi 42: 98-122, 2014 (In Chinese).

13. Agatston AS, Janowitz WR, Hildner FJ, Zusmer NR, Viamonte $\mathrm{M} \mathrm{Jr}$ and Detrano R: Quantification of coronary artery calcium using ultrafast computed tomography. J Am Coll Cardiol 15: 827-832, 1990.

14. Bild DE, Detrano R, Peterson D, Guerci A, Liu K, Shahar E, Ouyang P, Jackson S and Saad MF: Ethnic differences in coronary calcification: The multi-ethnic study of atherosclerosis (MESA). Circulation 111: 1313-1320, 2005.

15. Hoffmann U, Massaro JM, Fox CS, Manders E and O'Donnell CJ: Defining normal distributions of coronary artery calcium in women and men (from the Framingham Heart Study). Am J Cardiol 102: 1136-1141, 2008.

16. Loria CM, Liu K, Lewis CE, Hulley SB, Sidney S, Schreiner PJ, Williams OD, Bild DE and Detrano R: Early adult risk factor levels and subsequent coronary artery calcification: The CARDIA Study. J Am Coll Cardiol 49: 2013-2020, 2007.

17. Mosseri M, Satler LF, Pichard AD and Waksman R: Impact of vessel calcification on outcomes after coronary stenting. Cardiovasc Revasc Med 6: 147-153, 2005.

18. Sharma RK, Sharma RK, Voelker DJ, Singh VN, Pahuja D, Nash T and Reddy HK: Cardiac risk stratification: Role of the coronary calcium score. Vasc Health Risk Manag 6: 603-611, 2010.

19. Greif M, Arnoldt T, von Ziegler F, Ruemmler J, Becker C, Wakili R, D'Anastasi M, Schenzle J, Leber AW and Becker A: Lipoprotein (a) is independently correlated with coronary artery calcification. Eur J Intern Med 24: 75-79, 2013.

20. Ping Q, Li Y, Jia Y, et al: Correlationg between endothelin-1 and coronary artery calcification. Chin J Geriatr Heart Brain Vessel Dis 15: 916-919, 2013.

21. Csiszar A, Smith KE, Koller A, Kaley G, Edwards JG and Ungvari Z: Regulation of bone morphogenetic protein-2 expression in endothelial cells: Role of nuclear factor-kappaB activation by tumor necrosis factor-alpha, $\mathrm{H}_{2} \mathrm{O}_{2}$, and high intravascular pressure. Circulation 111: 2364-2372, 2005.

22. Block GA, Klassen PS, Lazarus JM, Ofsthun N, Lowrie EG and Chertow GM: Mineral metabolism, mortality, and morbidity in maintenance hemodialysis. J Am Soc Nephrol 15: 2208-2218, 2004.

23. Shin S, Kim KJ, Chang HJ, Cho I, Kim YJ, Choi BW, Rhee Y, Lim SK, Yang WI, Shim CY, et al: Impact of serum calcium and phosphate on coronary atherosclerosis detected by cardiac computed tomography. Eur Heart J 33: 2873-2881, 2012.

24. Qiao H, Wu Y and Zeng H: Progress of coronary artery calcification. Adv Cardiovasc Dis. 31: 715-718, 2010.

25. Osto E, Fallo F, Pelizzo MR, Maddalozzo A, Sorgato N, Corbetti F, Montisci R, Famoso G, Bellu R, Lüscher TF, et al: Coronary microvascular dysfunction induced by primary hyperparathyroidism is restored after parathyroidectomy. Circulation 126: 1031-1039, 2012.

26. Klarić D, Klarić V and Kristić I: Cardiac valves calcifications in dialysis patients. Acta Med Croatica 65 (Suppl 3): 11-13, 2011 (In Croatian). 
27. Choi HS, Kim SH, Rhee Y, Cho MA, Lee EJ and Lim SK: Serum parathyroid hormone is associated with carotid intima-media thickness in postmenopausal women. Int J Clin Pract 62: 1352-1357, 2008.

28. Buizert PJ, van Schoor NM, Simsek S, Lips P, Heijboer AC, den Heijer M, Deeg DJ and Eekhoff EM: PTH: A new target in arteriosclerosis? J Clin Endocrinol Metab 98: E1583-E1590, 2013.

29. Nuzzo V, Tauchmanovà L, Fonderico F, Trotta R, Fittipaldi MR, Fontana D, Rossi R, Lombardi G, Trimarco B and Lupoli G: Increased intima-media thickness of the carotid artery wall, normal blood pressure profile and normal left ventricular mass in subjects with primary hyperparathyroidism. Eur J Endocrinol 147: 453-459, 2002.

30. Reis JP, von Mühlen D, Michos ED, Miller ER III, Appel LJ, Araneta MR and Barrett-Connor E: Serum vitamin D, parathyroid hormone levels, and carotid atherosclerosis. Atherosclerosis 207: 585-590, 2009.
31. Ix JH, Katz R, Kestenbaum B, Fried LF, Kramer H, Stehman-Breen C and Shlipak MG: Association of mild to moderate kidney dysfunction and coronary calcification. J Am Soc Nephrol 19: 579-585, 2008.

32. Fox CS, Larson MG, Keyes MJ, Levy D, Clouse ME, Culleton B and O'Donnell CJ: Kidney function is inversely associated with coronary artery calcification in men and women free of cardiovascular disease: The Framingham Heart Study. Kidney Int 66: 2017-2021, 2004.

33. Kramer H, Toto R, Peshock R, Cooper R and Victor R Association between chronic kidney disease and coronary artery calcification: The Dallas Heart Study. J Am Soc Nephrol 16: 507-513, 2005

34. ElBarzouhi A,Elias-SmaleS,DehghanA,Vliegenthart-ProençaR, Oudkerk M, Hofman A and Witteman JC: Renal function is related to severity of coronary artery calcification in elderly persons: The Rotterdam study. PLoS One 6: e16738, 2011. 